\title{
Justicia y democracia: Dos siglos de inacabada discusión (Con coda pensando en Chile)
}

\author{
Justice and Democracy: Two Centuries of Unfinished Discussion (With a Coda on Chile)
}

\author{
ROBERTO GARGARELLA*
}

\section{INTRODUCCIÓN}

En lo que sigue, quisiera reflexionar sobre el largo e inacabado diálogo que viene desarrollándose, desde hace décadas, en torno a la justificación del control judicial.

Conforme veremos, desde el mismo momento en que comienza a pensarse sobre la posibilidad de que los jueces invaliden una ley, empieza a cuestionarse el derecho de que los jueces puedan imponer sus criterios sobre el significado de la Constitución, por encima de la política. Desde entonces a hoy, desde el centro y desde la periferia en la que muchos nos encontramos, hemos estado conversando y debatiendo crítica, a veces enojosamente, acerca de los alcances, límites y posibilidades del control judicial de constitucionalidad. A continuación voy a presentar una breve reconstrucción de la disputa teórica que se ha dado en la materia, desde fines del siglo XVIII hasta la actualidad. Para ello, voy a dividir la evolución de esa conflictiva disputa en 5 etapas o movimientos -las cuales, como cualquier otra clasificación, tienen algo de arbitrario. Presento en lo que sigue esta clasificación de modo propositivo y provisional, identificando a cada una de esas etapas con algún o algunos fallos judiciales, algunos autores, y algunos puntos de discusión particulares, que nos ayudarán a reconocer mejor- o así lo espero al menos- la evolución de esta conversación.

\section{LAS CINCO ETAPAS}

\section{i) El momento fundacional}

El momento fundacional del debate en torno a la revisión judicial de las leyes aparece en los Estados Unidos, al tiempo en que se terminaba de escribir lo que luego sería la primera Constitución Federal de ese país. Por entonces, muchos de los críticos de ese (todavía) proyecto de Constitución (que necesitaba ser aprobado en todos los diferentes estados antes de convertirse en Constitución de la Nación), comenzaron a concentrar parte de sus objeciones en lo que veían como una ofensa al espíritu federalista que animaba a (y que había originado, de hecho) las conversaciones constitucionales. Para muchos, la decisión de contar con un tribunal común -una Corte Suprema- con la facultad de invalidar las decisiones que pudieran

* Universidad Torcuato di Tella, Argentina y Universidad de Buenos Aires, Argentina

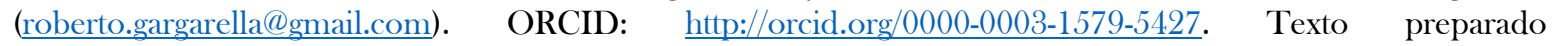
originariamente para prologar el libro La justicia constitucional de la democracia deliberativa, de Roberto Niembro Ortega: NIEMBRO (2019). 
tomarse al interior de cada uno de los estados de la Unión, resultaba una afrenta imposible de digerir. Fueron varios los críticos antifederalistas (así se los llamó) de ese esquema todavía en ciernes, que disputaron palmo a palmo cada una de las iniciativas federalistas. Entre tales críticos, uno de los más destacados y que más insistentemente planteaba objeciones frente a la organización judicial propuesta, firmaba sus artículos como Brutus (un activista político cuya identidad todavía no resulta totalmente clara).

Frente a tal línea de críticas, Alexander Hamilton fue el primero en reconocer la seriedad de esos cuestionamientos, y tratar de salir al cruce de ellos. Hamilton atendería tales cuestionamientos en un magnífico texto, ahora conocido como El Federalista № 78. Allí, con extraordinaria lucidez (y más allá de sus errores y sesgos conservadores) Hamilton procuró de dar cuenta de todas las críticas que reconoció como relevantes, frente al diseño constitucional propuesto por los federalistas en materia de organización judicial. Dentro de los muchos temas que trata allí, con profundidad y síntesis ejemplares (la proveniencia y formación de los jueces; las razones de su estabilidad; la relación entre las distintas ramas de poder; las formas de designación judicial; etc.), Hamilton se refiere también, por primera vez, a la crítica "democrática" insinuada por "Brutus" contra la judicial review. Hamilton es entonces quien, antes que nadie, sale a proporcionar una respuesta fuerte contra la reclamada falta de legitimidad de los jueces para controlar la validez de las leyes. Él sostiene entonces, casi al pasar (y pensando en las objeciones de "Brutus", aunque sin mencionarlo):

El derecho de los tribunales a declarar nulos los actos de la legislatura, con fundamento en que son contrarios a la Constitución, ha suscitado ciertas dudas como resultado de la idea errónea de que la doctrina que lo sostiene implicaría la superioridad del poder judicial frente al legislativo.

Hamilton ofreció entonces la primera gran respuesta frente a la crítica al control judicial. Y fue una gran respuesta por el tenor de su argumento, que de modo pionero trató de dar cuenta del problema "democrático". Lo que sostuvo Hamilton, en los hechos, fue no había nada anti-democrático en la invalidación judicial de una ley, en tanto y cuanto dicha invalidación se fundara en la contradicción entre esa ley cuestionada y la Constitución. Y ello así, porque era la Constitución, y no la ley, la que encerraba la verdadera "voluntad del pueblo." En un sistema con supremacía constitucional -concluyó Hamilton- resultaba simplemente obvio que debía prevalecer la voluntad del pueblo expresada en la Constitución, antes que la voluntad "delegada" de la legislatura, ocupada por meros mandatarios ocasionales del pueblo. En sus términos: "si ocurriere que entre las dos [la Constitución y la ley] hay una discrepancia, debe preferirse, como es natural, aquella que posee fuerza obligatoria y validez superiores; en otras palabras, debe preferirse la Constitución a la ley ordinaria, la intención del pueblo a la intención de sus mandatarios".

Expresado allí, en esos pocos renglones, el argumento de Hamilton recorrería exitosa, triunfalmente, casi incuestionado, buena parte de la discusión constitucional temprana de las Américas. Ello así, en particular, a partir de la recepción de dicho argumento, en 1803, en la histórica decisión escrita por el juez Marshall, en Marbury v. Madison, 5 U.S. (1 Cranch) 137. La opinión de Marshall, más que el argumento de Hamilton, fue lo que quedó en la historia, pero lo cierto es que todo lo importante que señalara Marshall en su fallo ya estaba contenido 
en el razonamiento de Hamilton que, en todo caso, Marshall corona en su opinión sobre el caso, sosteniendo que,

Hay sólo dos alternativas demasiado claras para ser discutidas: o la Constitución controla cualquier ley contraria a aquélla, o la Legislatura puede alterar la Constitución mediante una ley ordinaria. Entre tales alternativas no hay términos medios: o la Constitución es la ley suprema, inalterable por medios ordinarios; o se encuentra al mismo nivel que las leyes y de tal modo, como cualquiera de ellas, puede reformarse o dejarse sin efecto, siempre que al Congreso le plazca.

Notablemente, con Marbury v. Madison, el debate que se abría poderosamente en 1787, en torno al control judicial, termina cerrándose violentamente, como si la discusión previa no hubiera tenido razón de ser, o hubiera sido resuelta definitivamente, a través de la demostración contundente de los errores argumentativos de los entonces críticos. En términos de Robert Cover, Marbury v. Madison aparece como una decisión jurispathic que se impuso suprimiendo lecturas alternativas, en lugar de venir a enriquecer el debate entonces naciente y todavía vigoroso. ${ }^{1}$ Hasta fines del siglo XIX, ese debate quedaría básicamente adormecido, lo cual nos permitiría hablar de esta primera y gran etapa fundacional de la discusión sobre el control judicial como una etapa de debate clausurada luego de la decisión de Marshall.

\section{ii) El consenso se resquebraja. La "era Lochner" y el renacimiento del Estado} intervencionista

La segunda gran etapa de esta discusión se abre cuando el contundente silencio impuesto por Marbury v. Madison comienza a resquebrajarse -algo que empieza a ocurrir, de manera saliente, a fines del siglo XIX, esto es decir, casi un siglo después de que el debate se abriera por primera vez. Son muchas las razones que nos permiten entender la ruptura de ese consenso, pero algunas de ellas tienen que ver con el papel protagónico que reclaman para sí las ramas ejecutiva y legislativa, ante una pax económica que se había ido deteriorando con el correr de los años. En efecto, entre fines del siglo XIX y comienzos del siglo XX, el viejo orden social y económico -que se sintetizara en América Latina con la noción de Orden y Progresoaparece desgastado, y el conflicto social comienza a agudizarse, de modo tal vez imprevisto, en los ámbitos geográficos más diferentes. Esa quiebra del viejo orden parece hacer un llamado a la intervención activa del Estado, único agente capaz de coordinar esfuerzos y voluntades en pos de la reconstrucción de una sociedad en crisis.

En los Estados Unidos, nace por entonces el "Estado Benefactor" -el que impulsaría las políticas del llamado New Deal-orientado a confrontar la situación de crisis social, a través de una fuerte intervención gubernamental en la organización económica del país. Notablemente -y éste es el punto que más me interesa destacar por el momento- fue el Poder Judicial el que tomó la vanguardia en ese momento, con el objeto de detener el "embate regulador" del Estado. Una y otra vez, desde entonces, la Corte Suprema de los Estados Unidos invalidó las iniciativas provenientes de la política -iniciativas habitualmente resultantes de un acuerdo entre

' COVER (1983). 
las ramas legislativa y ejecutiva, que llegaron a contar con un amplio respaldo popular. El hecho de que, durante años, fuera el Poder Judicial -encarnado por la Corte de los Estados Unidosel que impidiera la aplicación del New Deal; enfrentara a las iniciativas presidenciales (en particular, del Presidente Roosevelt); y retrasara peligrosamente la salida de la crisis, generó una fuerte oleada de cuestionamientos ante la renovada y activa práctica de la judicial review.

El caso que pasó a sintetizar el espíritu anti-político/anti-regulador del momento fue el que se resolvió con el fallo Lochner v. New York, 198 U.S. 45 (1905). Dicho caso inauguró una notable seguidilla de decisiones, dirigidas a invalidar (en casi dos centenares de casos) distintas iniciativas de intervención estatal en la economía. Lo ocurrido en los Estados Unidos, finalmente, llevó a su máxima expresión (y una de las más graves) un fenómeno que en términos similares se daba, más o menos al mismo tiempo, en otros países del mundo (en la Argentina, por ejemplo, y por aquellos años, se produjeron sucesos bastante parecidos, con un Estado crecientemente regulador de la economía, y una Corte -presidida por Antonio Bermejo- que en nombre de los ideales "fundacionales", y una lectura originalista de la Constitución, se empeñó durante años en retrasar la consolidación del "Estado interventor"). Finalmente, el "embate judicial” terminaría en un fracaso y -en los Estados Unidos y en el mundo- la causa simbolizada por el New Deal terminaría por imponerse. En dicho respecto, la decisión West Coast Hotel Co. v. Parrish, 300 U.S. 379, aparecida en 1937 (más de 30 años después de Lochner), señalaría el final definitivo de la era anterior -la llamada "era Lochner". La mayoría anti-estatista que había prevalecido en la Corte, desde "Lochner”, cedía ahora lugar a una nueva, abierta y sensible a las iniciativas del Estado regulador.

En términos académicos, el viejo consenso existente en torno de la línea HamiltonMarshall también terminó por resquebrajarse en estos años, acompañando el desmoronamiento del viejo orden económico pretendidamente fundado en el Estado Spenceriano/Smithiano del "dejar hacer." En la ruptura del viejo acuerdo, resultaron cruciales posiciones como las defendidas por James Thayer en su famoso artículo "The Origin and Scope of the American Doctrine of Constitutional Law," de 1893. En dicho texto, de modo pionero, y casi solitario, Thayer avanzó una crítica significativa contra las pretensiones de la justicia de imponer su autoridad y criterios sobre la política.

La crítica de Thayer se remontaba al argumento del juez Marshall en Marbury v. Madison, afirmando la necesidad de completar y corregir el razonamiento de aquél. Thayer se preguntaba qué es lo que podía tornar aceptable una decisión tan dramática como la de invalidar la ley. En su respuesta, él sostuvo que sólo podía admitirse una decisión semejante en casos en donde no quepan dudas acerca de la inconstitucionalidad de la ley, en donde la misma sea "tan manifiesta que no deje lugar para la duda razonable." Este simple principio es el que da origen a la llamada doctrina del "error manifiesto." La base en la que se apoyaba Thayer para sostener este criterio restrictivo resultaba muy simple también. En su opinión, la Constitución "admite habitualmente diferentes interpretaciones," dejándole al legislador "un abanico amplio de opciones," todas ellas racionales. El juez, entonces -continuaba el argumento- no puede pretender, frente al legislador, que predomine la posición que le resulta (a él, como juez) la más adecuada. Sólo en caso de que lo actuado por el legislador exceda claramente el marco de las interpretaciones razonables de la Constitución, entonces, el juez puede llegar a desafiar e invalidar lo hecho por la legislatura. 
Dentro del derecho norteamericano, la postura defendida por Thayer comenzó a ganar respaldo creciente, con el paso de los años. Ello así, en el ámbito académico, de la mano de llamado realismo jurídico; y en el ámbito judicial, a partir de las numerosas decisiones que vinieron a respaldar las regulaciones económico-sociales impuestas en la época del New Deal. Jueces de extraordinario renombre como Learned Hand, Felix Frankfurter o, muy especialmente, Oliver Wendell Holmes se encuentran entre los que adhirieron a criterios semejantes, inclinándose por la regla de la presunción en favor de las mayorías. ${ }^{2}$ Todos los juristas mencionados aparecen básicamente unidos por su común reclamo en favor de una cierta restricción del poder judicial, en su tarea de custodio de la Constitución. En el desarrollo de sus escritos y sentencias, han dado fuerza a una corriente que se distingue en su afirmación de una clara presunción en favor de las opiniones del legislador democrático. La política -y no la justicia- era la que estaba llamada a decidir y prevalecer en contextos de crisis económica tan profunda como la señalada.

\section{iii) Activismo social en contra de la discriminación legislativa. La Corte Warren y "Brown vs. Board of Education"}

Según viéramos, el primer gran momento del debate en torno a la revisión judicial de las leyes fue el "momento fundacional," que tuvo su centro en el fallo Marbury v. Madison: se trató de la etapa en donde se afirmó como respuesta sólida e indiscutible la del control de constitucionalidad, frente a los primeros cuestionamientos hechos en nombre de la autoridad legislativa. El segundo momento de ese debate -también lo vimos- tuvo que ver con un movimiento de ruptura, en donde aquel consenso inicial ("Hamilton-Marshall”) terminó por resquebrajarse, en particular luego de la obstinada negativa de la justicia a autorizar intervenciones -desde todo punto de vista razonables y permisibles- de la política, en el ámbito económico. Así, mientras que la primera etapa se había dirigido a consolidar la práctica de la judicial review, aún frente al argumento democrático; en la segunda, la potencia del argumento democrático pareció renacer hasta terminar imponiéndose, en su reclamo de primacía para la política: en una sociedad democrática -pareció afirmarse entonces- era la voz de la ciudadanía, resumida en el Congreso de la Nación, la que debía terminar primando en la resolución de los asuntos públicos. En la tercera gran etapa que vamos a explorar ahora, el acuerdo anterior "anti-judicial" pareció quedar puesto "cabeza abajo". Nos encontramos ahora en un momento en donde algunos tribunales activistas y de avanzada, comienzan a desafiar sistemáticamente las discriminaciones raciales creadas, amparadas o sostenidas por la política. Dicho arriesgado y valiente comportamiento judicial, de confrontación con iniciativas legislativas no igualitarias

\footnotetext{
${ }^{2}$ En su conocida disidencia en el caso Lochner v. New York, el juez Holmes sostuvo que el tribunal estaba decidiendo el caso meramente a partir de su adhesión a una peculiar doctrina económica que la mayoría del país no sostenía. "Si lo que se me preguntara fuera si yo adhiero o no a dicha teoría, querría estudiarla más y recién luego tomar una decisión. Pero entiendo que no es éste mi deber, dado que creo férreamente que mi acuerdo o desacuerdo con una teoría como la citada no tiene nada que ver con el derecho de la mayoría a incorporar sus visiones dentro del derecho." "Entiendo que el término libertad que aparece en la Enmienda Catorce resulta corrompido -concluyó Holmes- cuando se lo utiliza para impedir el resultado natural de la opinión dominante, y en tanto no pueda mostrarse que el hombre equitativo y racional admitiría, necesariamente, que la norma propuesta infringe principios fundamentales entendidos como tales por las tradiciones de nuestro pueblo y nuestro derecho."
} 
-iniciativas muchas veces racistas, directamente- generaron una entusiasta adhesión en la doctrina, que prontamente, y sin mayores justificaciones, comenzó a suscribir una posición directamente contrapuesta a la posición (hostil al activismo judicial) que había defendido hasta hace pocos años.

Si la "nave insigne” de la etapa anterior había sido el fallo Lochner, capaz de marcar toda una era de activismo judicial injustificable; la nueva etapa quedó marcada por el caso Brown $v$. Board of Education of Topeka, 347 U.S. 483 (1954), que pasó a simbolizar también, por sí mismo, toda una nueva era, ésta vez, en apariencia, de activismo judicial necesario, reclamado y justificado. Brown fue el caso más representativo de los decididos por la Corte presidida por Earl Warren -la "Corte Warren”- que se caracterizó por sus numerosas decisiones favorables a la igualdad y los derechos civiles. Tales decisiones no sólo frenaron las políticas de segregación en las escuelas públicas (Brown v. Board of Education); sino que consagraron el derecho de privacidad que no aparecía claramente enunciado en la Constitución norteamericana (Griswold v. Connecticut); invalidaron el rezo obligatorio o la lectura obligatoria de la Biblia en las escuelas públicas (Engel v. Vitale; Abington School District v. Schempp); impidieron que se socave el voto de las minorías a través del rediseño arbitrario de los distritos electorales (Baker v. Carr); o definieron el derecho a la no autoincriminación (Miranda v. Arizona); entre muchas otras resoluciones de peso.

La doctrina que "nació y creció" con Brown y la Corte Warren fue amplia y diversa, y ella, de algún modo, sigue liderando la discusión hasta nuestros días (aunque, como veremos, con muchas fracturas desde entonces). Otra vez, y gracias al impacto de ver a los tribunales liderando una supuesta cruzada a favor de la protección de las minorías, muchos académicos pasaron a abrazar y justificar decididamente el activismo judicial en la invalidación de decisiones políticas. El libro que, en la época, volvió a mover las aguas de la discusión teórica en torno al control judicial, volviendo a poner el tema en el primer plano, fue The Least Dangerous Branch, de Alexander Bickel, publicado en 1962. En ese texto, Bickel ofreció una justificación del control judicial que partía, sin embargo, del reconocimiento del serio problema en juego: la invalidación de las leyes por parte de los tribunales representaba una afrenta a la voluntad popular del "aquí y ahora", que requería ser justificada, antes que simplemente asumida. Fue Bickel, en este libro, quien puso en discusión definitiva a la "dificultad contramayoritaria” que afectaba al Poder Judicial. Luego de la aparición del libro de Bickel, tal vez la respuesta jurídica más sofisticada e interesante de todas las que aparecieron entonces, en defensa de un intenso judicial review, fue la ofrecida por el filósofo del derecho norteamericano Ronald Dworkin. ${ }^{3}$ En sus primeros escritos en la materia, principalmente, Dworkin justificó un modo de decisión judicial extenso y profundo, que ilustró con la figura de un imaginario "juez Hércules" orientado a proteger minorías desaventajadas; que tomaba los "derechos en serio", y actuaba guiado por una fuerte (aunque dudosa) distinción entre “derechos” y "políticas”. En escritos posteriores, Dworkin cambiaría esa presentación más bien extrema, moderaría algunos de sus asertos, y calificaría su apoyo enfático a la revisión judicial, para terminar afirmando una defensa "condicional" de la judicial review. ${ }^{4}$ En todo caso, su

\footnotetext{
${ }^{3}$ Por ejemplo, en DWORKIN (1977, 1985, 1986).

‘Así, por ejemplo, en DWORKIN (1996), en la que presenta “una lectura moral de la Constitución”.
} 
postura doctrinaria favorable a un activo control judicial, lideraría los estudios constitucionales de la época. Muchos otros autores, entre los que destacaría a Owen Fiss -también de amplia influencia en América Latina- secundaron a Dworkin desde una posición claramente alineada con lo que fuera el "sueño inicial" de tribunales igualitarios y defensores de minorías postergadas -un sueño alimentado por el particular activismo de la Corte Warren."

Sobre el final de esta etapa -en 1980- John Ely publicaría un importantísimo libro Democracy and Distrust- a través del cual presentaría una defensa procedimentalista de la revisión judicial. Ely apoyó dicha renovada defensa del control judicial en la historia jurídica norteamericana, y en particular, en los criterios avanzados por la propia Corte norteamericana en "la nota al pie más citada" en la historia de dicha jurisprudencia -la nota al pie n. 4, que apareciera en el caso United States v. Carolene Products, 304 U.S. 144, 152, de 1938. Esa defensa procedimentalista del control judicial -que deslumbrara aún a filósofos políticos notables, como Jürgen Habermas- ganó especial atractivo. ${ }^{6}$ Ello así, tal vez, porque ofreció razones sólidas para mostrar por qué el tipo de activismo judicial predominante durante los años de la "era Lochner" resultaba inaceptable, pero también, y al mismo tiempo, demostrar por qué el tipo de activismo judicial propio de la "Corte Warren” podía resultar defendible. Básicamente, lo que sostuvo Ely es que la invalidación judicial de la legislación era inaceptable cuando se dirigía a reemplazar los dictados "sustantivos" de la política (i.e., una política económica, como la del New Deah), pero aceptable si venía a resguardar los "procedimientos” o "reglas de juego" de la política democrática (i.e., garantizar que todos los jugadores "democráticos" puedan jugar el juego de la política). Como un árbitro en un partido de fútbol, la tarea del juez resultaba irreprochable si permitía que el juego se juegue, conforme a los requerimientos del reglamento del fútbol, pero impermisible si pretendía modificar el resultado del partido, por desacordar con sus resultados.

\section{iv) El consenso vuelve a romperse: "Quitando la Constitución de las manos de los tribunales"}

A los pocos años de instalado, el "nuevo consenso" crecido al calor de la "Corte Warren", terminaba por romperse. Fueron muchas las razones que ayudaron a esa nueva y definitiva ruptura, pero una motivación determinante, sin dudas, tuvo que ver con los cambios producidos al interior del mismo tribunal norteamericano -cambios que podemos simbolizar por el pasaje de la "Corte Warren" a la Corte comandada por el Justice Rehnquist. El hecho de que el máximo tribunal norteamericano pasara a ser re-colonizado, con violenta urgencia, por jueces de orientación conservadora, promovidos a esos puestos por políticos también conservadores -estamos en el tiempo de Ronald Reagan y Margaret Thatcher- demostró la fragilidad sobre la que se asentaba el acuerdo anterior. Finalmente, lo que resultaba cada vez más claro es que lo actuado por la Corte Warren hablaba menos de las virtudes del control judicial, que del valor de dicho control cuando ocasionalmente quedaba a cargo de jueces ideológicamente comprometidos con una visión igualitaria y protectora de las minorías. La hegemonía conservadora que comenzó a asentarse en los años 80 mostró del modo más crudo

${ }^{5}$ FisS $(1976,1978)$.

${ }^{6}$ Habermas (1992). 
que no había nada "propio" o "ínsito" en el control judicial, que garantizase o de algún modo permitiera pensar en la estabilidad de un tipo de intervención judicial, en principio muy atractivo, como el que se desplegara en los años de Brown. El hecho era, finalmente, que una mayoría política transitoria, de orientación conservadora, podía fill the Court con jueces conservadores, y así desmantelar prontamente toda ilusión de contar con una justicia alineada con la protección de los más vulnerables.

Irritados por el cariz conservador que comenzaba a teñir toda la vida pública, o molestos por una justificación del control judicial que se había demostrado frágil y finalmente frustrante en la práctica, muchos doctrinarios comenzaron a atacar ese nuevo, ilusorio consenso que la "Corte Warren” había contribuido a alimentar. No por azar, en esta etapa es cuando nace el movimiento de los "estudios críticos del derecho" (Critical Legal Studies, CLS), que retoma mucha de las banderas que el "realismo jurídico" de los años 30 había dejado instaladas. A partir del trabajo de los CLS, se empezó a hablar, otra vez, y como entonces, de la discrecionalidad de la justicia, y del "derecho como política." Son muchos los autores que destacan dentro de este revival de los estudios jurídicos críticos -Duncan Kennedy, David Kennedy, Mark Tushnet, entre tantos otros. Las tesis principales del movimiento quedarían resumidas en un artículo aparecido en el Harvard Law Review, y que luego se publica como libro en 1986, con la autoría del profesor brasileño Roberto Mangabeira Unger - The Critical Legal Studies Movement. Unger sintetizaría bien el malestar generado por el degradado desarrollo institucional del tiempo, refiriéndose a la "incomodidad con la democracia", a la que presentó como idea característica -como el "sucio y pequeño secreto"- de la vida política del fin de siglo. ${ }^{7}$

Es en estos años, también, cuando se publican dos poderosos libros que expresan muy bien la crítica radical que entonces comenzaba a solidificarse, contra la revisión judicial. Pienso, por un lado, en un libro publicado en 1999 por Mark Tushnet (uno de los fundadores del movimiento CLS): Taking the Constitution Away from the Court, esto es decir "quitando la Constitución de las manos de los tribunales”. En el mismo año, aparece un nuevo libro escrito por otro de los grandes autores y líderes del "embate anti-judicial” del momento, Jeremy Waldron. Pienso, en particular, en su libro Law and Disagreement, que sintetiza una labor de años, del autor, reflexionando críticamente en torno al control judicial. ${ }^{8}$ Para Waldron, en sociedades heterogéneas, marcadas por genuinos "desacuerdos" valorativos (desacuerdos, en particular, sobre el significado de nuestros compromisos públicos o constitucionales más importantes), y compuestas por individuos "iguales" en cuanto a su dignidad moral, el control judicial (y su pretensión de decidir con carácter final todos esos desacuerdos) resultaba "ofensivo" o directamente "insultante" -así, según llegara a escribir Waldron en algunos de sus escritos tempranos en la materia. ${ }^{9}$

Conforme entiendo, muchos nos incorporamos a la discusión sobre la revisión judicial en esta etapa (fines de los 80), plena de nuevas meditaciones críticas en torno al judicial review.

\footnotetext{
${ }^{7}$ UNGER (1996), p. 72.

${ }^{8}$ WALDRON (1999a), y también WALDRON (1999b).

${ }^{9}$ WALDRON (1993).
} 
En América Latina, de hecho, la doctrina constitucional dominante parecía ignorar, esencialmente, los debates en la materia -en mi opinión, por desdén, o por comodidad, asentada como estaba esa doctrina en el "consenso de Marbury v. Madison". Quiero decir, la doctrina latinoamericana parecía descansar plácidamente en el primer y lejano acuerdo alcanzado en la materia, y gestado a fines del siglo XVIII: desde entonces, nuestros doctrinarios parecieron asumir que la discusión sobre el tema se encontraba resuelta, fundamentalmente saldada. Fueron muy pocos los autores que, en la región, ayudaron a romper, poco a poco, ese aletargado consenso. En particular, destacaría los profundos estudios constitucionales de Carlos Nino, quien en pocos años publicaría algunos textos importantes en la materia -textos apropiadamente descriptivos de la discusión en curso, y a la vez críticos con ella. En sus últimos escritos, Nino parece abrazar una posición revisada y alerta, que construye a partir de la postura procedimentalista avanzada en su momento por John Ely. ${ }^{10}$ En lo personal, y al calor de las enseñanzas y textos de Carlos Nino, me fui incorporando de a poco a esa discusión ya madura en el ámbito internacional, y todavía muy incipiente en América Latina. En 1991 completé mi tesis doctoral en la Universidad de Buenos Aires -una tesis que, según entiendo, fue de los primeros trabajos en la región que recuperaron críticamente las discusiones doctrinarias que se encontraban en boga en el momento, en torno a la "dificultad contramayoritaria". Dicha tesis, publicada varios años después (en 1996) asumía una postura radicalmente crítica sobre el control judicial, muy en línea con posturas como las de Tushnet y Waldron que, en mi libro de entonces, jugaban sin embargo un papel muy marginal. Mi postura en la materia aparecía, más bien y de modo especial, apoyada en estudios sobre la democracia deliberativa como los que el propio Nino había traído y hecho conocer en la región.

\section{v) Desde "el fin de la última palabra," al giro deliberativo: una justificación limitada del control judicial}

Paso ahora a concentrarme en la que presentaré, provisionalmente, como la "última" etapa significativa en la discusión desarrollada en torno a la justificación del control judicial. Esta etapa, en buena medida, parece sofisticar a la anterior: el "embate radical" contra la revisión judicial aparece ahora refinado y pulido, en particular -pero no exclusivamente- a la luz de complejas teorías sobre la democracia; teorías interpretación constitucional; y estudios politológicos sobre la motivación judicial (y la "judicialización de la política"). Encontramos aquí un debate ya asentado y maduro en la materia, en el que participan ya, y de modo activo, una notable cantidad de autores no-anglosajones, entre los que mencionaría -dejando de lado sin dudas a cantidad de otros brillantes partícipes de esta discusión- a los españoles Juan Carlos Bayón y Víctor Ferreres (de fuerte presencia e influencia en la región); a Micaela Alterio; Helena Alviar; Paola Bergallo; Miguel Godoy; Juan González Bertomeu; Conrado Hubner Mendes; Isabel Jaramillo; Julieta Lemaitre; Sebastián Linares; Roberto Niembro; Xisca Pou y Jorge Roa. ${ }^{11}$ En todo caso, y llegados a este punto, quisiera detenerme aquí unos instantes para

\footnotetext{
${ }^{10}$ Por ejemplo, NinO $(1992,1993)$.

${ }^{11}$ Alterio y Niembro (2017); Alviar y Lemaitre (2016); Bayón (1998); Bergallo (2005); Bertomeu (2011); FERRERES (2007); GODOY (2017); HÜBNER MENDES (2011, 2013); JARAMILlO (2008); LinARES (2008); Niembro (2019); POU (2011); ROA (2019).
} 
explicar de qué modo es que llegamos a esta situación de "debate ampliado", y por dónde es que creo que se encuentran circulando los debates, en este tiempo.

Dentro de esta discusión vasta, ya muy precisa y sofisticada, destacaría en particular una serie de debates, que creo que tuvieron un impacto importante en el desarrollo de nuestras reflexiones. Me refiero a debates que surgieron sobre todo en los años 90, relacionados con el papel que la ciudadanía tenía, había tenido, y en todo caso merecía tener, en el tratamiento y decisión efectiva de los problemas públicos más importantes; y que contrastaban con estudios críticos sobre el papel que tenían, habían tenido y en todo caso merecían tener los tribunales, en dicha materia. Esta línea de trabajos había encontrado un espectacular impulso en la Universidad de Yale, a partir de la línea de trabajos que comenzara a avanzar, desde 1991, el profesor Bruce Ackerman, en torno al papel de We the People en la creación e interpretación constitucionales. ${ }^{12}$ Otros profesores de la misma Universidad contribuyeron decisivamente en el desarrollo de esta línea de pensamiento. Me refiero, en particular, a los escritos elaborados por los profesores Reva Siegel y Robert Post, fundadores de lo que se dio en llamar el constitucionalismo democrático. A través de sus trabajos (que continuaban a los de Ackerman, pero que reconocían un claro anclaje en los pioneros escritos de Robert Cover) ellos ayudaron a entender el modo en que movimientos sociales como el de los derechos civiles o el feminismo, habían jugado, podían jugar, y merecían jugar un papel protagónico a la hora de moldear los contenidos y sentidos del derecho. ${ }^{13}$ Por otro lado, libros como el de Gerald Rosenberg, de 1991, ayudaron a re-dimensionar cuál había sido el papel efectivo de los tribunales de las épocas "gloriosas" (como la Corte Warren en los tiempos del fallo Brown): lo que resultaba cada vez más claro era que, sin la intervención activa de la política, ninguna decisión igualitaria o de transformación social promovida desde los estrados judiciales podía tornarse posible. Las decisiones "centradas en los tribunales" y "de arriba abajo" no habían tenido ni podía esperarse que tuvieran el poder transformador propio de las hadas, que alguna vez, parte de la doctrina, les había querido atribuir.

Junto con todos los trabajos anteriores, quisiera subrayar, de modo especial, la influencia proveniente de otra línea de investigación. Me refiero a trabajos que quedaron inscriptos dentro de lo que se denominó el constitucionalismo popular. Al interior de este campo podemos incluir, por caso, escritos como los publicados por Larry Kramer, ${ }^{14}$ Jack Balkin, ${ }^{15}$ y Richard Parker, ${ }^{16}$ entre otros. Las investigaciones de Kramer, en particular, muy atentas a la historia constitucional norteamericana, ayudaron a reconocer que, desde un comienzo (desde lo que denominamos el "momento fundacional" de la discusión) el control judicial de constitucionalidad era reconocido como un problema difícil de aceptar y justificar, antes que como la solución obvia frente a todos los grandes conflictos públicos -ello así, sobre todo cuando dicho control se llevaba a cabo en la modalidad que se convirtiera en dominante desde Marbury v. Madison, esto es decir, con tribunales arrogándose para sí la "última palabra.” Los aportes del "constitucionalismo popular" en la materia terminaron siendo muy iluminadores,

\footnotetext{
${ }^{12}$ ACKERMAN (1991).

${ }^{13}$ Post y Siegel (2004, 2007); Siegel (1996, 2004).

${ }^{14}$ Kramer $(2004,2005)$.

${ }^{15}$ BaLkin (1995).

${ }^{16}$ PARKER (1993).
} 
en este respecto, particularmente al distinguir entre dos cuestiones que merecían analizarse por separado, y no como si fueran lo mismo: la judicial review, y la última palabra en manos de los tribunales. Autores como Kramer contribuyeron a que todos los participantes de este debate distinguiéramos entre ambos aspectos habitualmente superpuestos, y reconociéramos que el real problema que nos ocupaba -a partir de nuestras compartidas preocupaciones democráticas- tenían que ver con lo último -tribunales arrogándose para sí la última interpretación de la Constitución- y no con lo primero -la existencia de controles no-políticos sobre los órganos políticos.

La distinción propuesta por los abogados del “constitucionalismo popular” tuvo, en los hechos, un impacto muy relevante según entiendo, tanto sobre la doctrina anglosajona como sobre la hispanoamericana. Por ejemplo, en parte a resultas de este tipo de distinciones, dos de los principales críticos del control judicial de constitucionalidad en el ámbito anglosajón Tushner y Waldron, ya nombrados- pasaron a revisar de modo relevante, aunque de ningún modo completo, sus críticas iniciales. Tushnet publicó en el 2008 un libro sobre las "Cortes débiles" frente a los "derechos fuertes," en el que se distanciaba de las posiciones maximalistas de su "quitando la Constitución de las manos de los tribunales": ahora, Tushnet reconocía la posibilidad de ejercicios más sensatos y moderados del control judicial, consistentes con sus preocupaciones democráticas. Del mismo modo, Waldron ya no consideraba el control judicial como un "insulto" a las mayorías, sino que limitaba su crítica contextualmente, relacionándola con la presencia de una serie de condiciones particulares (así, en su famoso texto "The Core of the Case," del 2009). Waldron, como Tushnet, reconocía que existían formas posibles de control judicial, sin última palabra, compatibles con nuestras intuiciones democráticas más asentadas. ${ }^{17}$

Muchos de nosotros confluimos en un lugar parecido a aquellos a los que llegaban Tushnet o Waldron, pero a partir de principios y compromisos teóricos diferentes, lo cual nos llevaría, también, a afirmar conclusiones en parte también diferentes a las de ellos. En mi caso, y según anticipara, resultaron fundamentales los estudios que realizara Carlos Nino, tratando de vincular la teoría de la democracia deliberativa con el análisis del control judicial. En varios de sus textos, y según lo adelantado, Nino terminó defendiendo una visión procedimentalista del control judicial (una visión que era capaz de discernir de acuerdo a principios claros y democráticos, entre las tareas de jueces y políticos), pero desde una concepción deliberativa de la democracia -lo cual generaba impactos significativos sobre la teoría de Ely, que aparecía apoyada, como buena parte de la teoría jurídica norteamericana, en una concepción restrictiva, "pluralista", de la democracia. ${ }^{18}$

Mis replanteos en la materia, entonces, tuvieron que ver no sólo con innovaciones como las aportadas por Nino, sino también con una nueva línea de reformas políticas y decisiones

\footnotetext{
${ }^{17}$ GONZÁlez BERTOMEU (2011).

${ }^{18}$ La "revisión" de Nino implicaba, ante todo, un recorte en las capacidades de la política para la toma de decisiones "sustantivas" -Nino entendía que de allí debían dejarse de lado las cuestiones de moral privada (que quedaban bajo el exclusivo control de cada individuo). Al mismo tiempo, y también a partir de ese renovado punto de apoyo -la democracia deliberativa- Nino consideraba que el control judicial sobre los procedimientos también debía repensarse -Nino comenzó a imaginar no sólo un control judicial más intenso sobre los debates políticos, sino también formas de intervención judicial más deliberativas.
} 
judiciales, de las que tuve conocimiento más detallado recién en esos años. Por un lado, para ese entonces (comienzos del siglo XX), se había desarrollado ya una impresionante literatura, impulsada sobre todo desde Canadá, y relacionada con el "diálogo judicial” -una literatura que había comenzado a expandirse extraordinariamente a partir de la Carta de Derechos de 1982. Dicha Carta de Derechos, recordemos, incluía la famosa cláusula del notwithstanding, destinada a devolverle la "voz" al Congreso, luego de una decisión judicial adversa (en este sentido, se trataba de una reforma que ponía en cuestión la idea de "última palabra” judicial). Sobre el final de mi tesis doctoral publicada en 1996, yo ya me refería al tema, con genuinas expectativas, y presentaba a la "cláusula del no-obstante" como una "promesa de salida" a la discusión, que mencionaba auspiciosamente (a la vez que aludía, al mismo tiempo, a la alternativa de "reenvío" judicial al legislativo). Sin embargo, sólo varios años después llegué a interiorizarme con algún detalle sobre dicha cláusula y la literatura elaborada en su torno, que ponía en el centro de la mesa de debates a lo que se empezaba a denominar el "constitucionalismo dialógico". Dicha literatura tomaba como punto de apoyo a la experiencia de Canadá, pero crecía desde allí, fronteras afuera, para encontrar otro punto de referencia clave en (lo que se denominara) el "nuevo modelo Commonwealth" sobre el control judicial -un "nuevo modelo" que impulsaban muchos países del Commonwealth, tradicionalmente hostiles al judicial review tradicional, pero ahora abiertos a experimentar con "Cartas de Derechos". ${ }^{19}$ Muchos de nosotros prestamos intensa atención a estos desarrollos, que prometían inscribir al control judicial -por fin- dentro de los dominios de una democracia deliberativa: conocíamos ahora que, en los hechos, era posible llevar adelante un control judicial en clave deliberativa, "devolviendo la última palabra” a la política.

Junto con este tipo de innovaciones y reformas institucionales que nos permitían replantear la "vieja discusión", aparecieron entonces toda una serie de decisiones judiciales que -mejor que cualquier otra alternativa teórica- demostraron que en la práctica era posible ejercer la tarea de control constitucional de un modo compatible con los exigentes requerimientos de una teoría democrática robusta, como la deliberativa. Tal vez la decisión judicial más relevante de esta nueva era -la decisión que, de algún modo, inauguró este nuevo ciclo de reflexión- fue la que adoptara la afamada Corte Sudafricana en Grootbom 2001 (1) SA 46 (CC). El caso en cuestión versó sobre un tema social urgente y muy preocupante (la ocupación ilegal de tierras), que la Corte de Sudáfrica decidió de un modo "modesto" y a la vez "revolucionario". La Corte reconoció que en el caso estaban en juego derechos sociales (constitucionalmente reconocidos) que eran violados por las autoridades políticas, y al mismo tiempo dejó en claro que era la política quien debía atender y reparar esas violaciones de derechos. De ese modo, y contra una mayoría de la doctrina que se negaba a reconocer status constitucional a los derechos sociales, la Corte afirmó el valor de esos derechos, y sostuvo que en el caso ellos estaban siendo vulnerados por el poder político (al no asegurar a los ocupantes ilegales, el derecho a vivienda que la Constitución reconocía). Por otro lado, y contra quienes decían que, en todo caso, tales derechos eran no-operativos (non-enforceable rights), la Corte sostuvo que los mismos sí debían ser respetados y asegurados en la práctica: la Constitución no mencionaba tales derechos sólo de un modo retórico. Más todavía, contra quienes decían

\footnotetext{
${ }^{19}$ Entre la amplísima literatura en la materia, destacan, por citar algunos, DIXON (2007); GARDBAUM (2013); Hogg y Bushell (1997); Hogg, Bushell y Wright (2007); Petter (2003); RoACH (2001, 2004); YOUNG (2012).
} 
que cualquier intervención de los tribunales en la materia sólo podía significar una intrusión inaceptable -anti-democrática- con la esfera de acción que pertenecía exclusivamente a la política, la Corte mostró la posibilidad de una respuesta perfecta: ella dejó en claro que el derecho en cuestión era operativo, y que debía asegurarse, pero a la vez sosteniendo que era la política quien tenía la obligación de asegurarlo, y no la propia justicia. El caso representó un revés fenomenal para parte significativa de la doctrina que, en algunos casos, admitió haberse equivocado o no-reconocido las posibilidades del activismo judicial en materia de derechos sociales, desarrollado de un modo compatible con el respeto de la autoridad democrática superior de las ramas políticas (el ejemplo de Sunstein [2001] resultó particularmente saliente, en este respecto).

Desde entonces, la Corte Sudafricana, y algunos otros tribunales del "sur global" (incluyendo, de modo especialmente saliente, los tribunales superiores de Colombia, la India y Costa Rica, y en ocasiones otros como los de la Argentina, México o Brasil) dieron sobradas muestras de imaginación y creatividad constitucionales, para conjugar su intervención en casos socialmente apremiantes y difíciles, con el respeto de la política, y la adecuación a las demandas de la democracia deliberativa. Iniciativas y prácticas tales como la del meaningful engagement, en Sudáfrica; las "audiencias públicas” y "mesas de diálogo" convocadas por varios de los tribunales latinoamericanos; las sentencias exhortativas; o el estado de cosas inconstitucional utilizado por la notable Corte Constitucional de Colombia (entre muchas otras innovaciones), ayudaron a cambiar el panorama en la materia, y permitieron una radical renovación en la discusión doctrinaria sobre el control constitucional. El "giro deliberativo" se había producido, y la idea de tribunales que "dialogaban" con los otros poderes; o provocaban u organizaban la discusión ciudadana; o apelaban a remedios de tipo "dialógico" en sus sentencias, pasó a convertirse en una realidad de todos los días. ${ }^{20}$

\section{CODA PENSANDO EN CHILE: ¿UNA NUEVA -SEXTA-ETAPA QUE SE ABRE?}

Llegados a este punto, quisiera simplemente dejar planteada algunas preguntas y dudas, relacionadas con las posibilidades de vincular la reflexión anterior con casos como el de Chile, que hoy se encuentra a las puertas de un cambio constitucional significativo. En lo personal, me parece importante, considero posible, pero estimo improbable, que Chile re-organice su estructura judicial para que ella funcione de un modo más “conversacional”, esto es decir, más en línea con los requerimientos de un debate público inclusivo. Hoy sabemos que escenarios como los planteados por el "constitucionalismo dialógico" ya no forman parte de la utopía constitucional (existen muchas experiencias actuales que muestran la factibilidad de reorientaciones semejantes, tal como discutimos más arriba); como también sabemos que hay buenas razones teóricas para alentar el desarrollo de las prácticas institucionales "dialógicas" (algunas de tales razones las hemos explorado más arriba). Me arriesgaría, incluso, a sostener lo siguiente: encontramos hoy, en Chile, algunas condiciones sociales que, en principio, parecen apropiadas para el desarrollo del diálogo constitucional. Pienso, en particular, en una

\footnotetext{
${ }^{20}$ DiXon (2007); Rodríguez-Garavito (2011); Tushnet (2009). En lo personal, procuré reunir varios de los principales aportes doctrinarios que conocí en la materia en GARGARELLA (2014); reflexioné críticamente sobre varias de tales experiencias y desarrollos teóricos en GARGARELLA (2015); y me encuentro completando un manuscrito sobre el tema, que todavía no he publicado, GARGARELLA (2019).
} 
ciudadanía "activa", "movilizada", y que se muestra interesada, dispuesta a, y capaz de, involucrarse en el debate de asuntos de directa relevancia constitucional. La "improbabilidad" que mencionaba en mi comentario anterior tiene que ver con otras cuestiones, vinculadas con ciertas condiciones materiales desfavorables -los niveles de desigualdad existentes- y con una historia de autoritarismo y poder concentrado (elementos, todos estos, comunes, aunque en distintos niveles, en toda la región). En tal respecto, entre las condiciones que parecen conspirar contra la emergencia y consolidación de un constitucionalismo más "dialógico" mencionaría, sobre todo, a ciertos factores institucionales desfavorables, hoy presentes en Chile -algunos de ellos reparables, y otros más difíciles de solucionar. Entre los déficits constitucionales reparables mencionaría, por caso, a una Constitución chilena como la actual, muy "espartana" o demasiado austera, en materia de derechos -algo que, esperablemente, resultará remediado en una próxima reforma constitucional. Existen, de todos modos, otros déficits, visibles todavía en la Constitución, y que no serán fáciles de reparar en el futuro, siquiera con algunas reformas constitucionales (para el caso, muy eventual, de que se implementen arreglos destinados a desconcentrar la actual organización del poder constitucional). El hecho es que Chile no sólo muestra una historia de asentado (híper)presidencialismo (capaz de bloquear o poner en crisis cualquier intento serio de hacer el enforcement de nuevos, hipotéticos, derechos sociales). El marco constitucional de Chile ofrece también (lo que es más grave en lo que aquí nos importa) una organización judicial elitista y vertical, que se combina con fuertes dificultades para el acceso (un restrictivo standing) de los más desaventajados a los tribunales. En dicho contexto, el desarrollo de prácticas dialógicas no resulta imposible, pero sin dudas aparece dificultado: en un marco institucional semejante, tales desarrollos van a terminar siendo dependientes, en un grado alto, de la voluntad (la "buena voluntad") más o menos discrecional de los propios funcionarios involucrados. Y, como nos enseñaba James Madison, ningún sistema institucional puede considerarse bien diseñado, en la medida en que los mejores resultados esperables dependan, finalmente, de la buena disposición de los encargados de implementarlos. 


\section{BIBLIOGRAFÍA CITADA}

Ackerman, B. (1991). We the People, Cambridge: Belknap Press.

Alterio, M. \& Niembro, R. (2013). "Constitucionalismo popular o el pueblo como actor protagónico”, Nexos, agosto 14.

Alterio, M. \& Niembro, R. (2017). La Suprema Corte y el matrimonio igualitario en México, México: UNAM.

Alviar, H. \& Lemaitre, J., et al. (2016). Constitución y democracia en movimiento, Bogotá: Universidad de los Andes.

BALkin, J. (1995). "Populism and Progressivism as Constitutional Categories," 104 Yale Law Journal 1935, 10.

BAYÓn, J.C. (1998). "Derechos, democracia y constitución", Discusiones Bahía Blanca, Argentina, n. 1, 65-94.

Bergallo, P. (2005). "Justice and Experimentalism". SELA 2005 <http://digitalcommons.law.yale.edu/yls_sela/44/> accesso 17 Diciembre 2013.

Bickel, A. (1962). The Least Dangerous Branch, Conn: Yale University Press.

Bonilua, D. (1993). Constitutionalism on the Global South. The Activist Tribunals of India, South Africa, and Colombia, Cambridge: Cambridge University Press.

Cover, R. (1983). "The Supreme Court, 1982 Term -- Foreword: Nomos and Narrative" (1983). Faculty Scholarship Series. 2705,

https://digitalcommons.law.yale.edu/fss_papers/2705

DiXON, R. (2007). “Creating Dialogue About Socio-economic Rights”, I.Con. vol. 5, n. 3, 391418.

DwORKIN, R. (1977). Taking Rights Seriously, London: Duckworth.

Dworkin, R. (1985). A Matter of Principle, Cambridge, Harvard University Press.

Dworkin, R. (1986). Law's Empire, Cambridge: Harvard University Press.

Dworkin, R. (1996). "The Moral Reading of the Constitution," The New York Time Review of Books, March 21st.

Ely, J. (1980). Democracy and Distrust, Harvard University Press.

FABre, C. (2000). Social rights under the Constitution. Government and the Decent life, Oxford University Press, Oxford.

Ferreres Comella, V. (2007). Justicia constitucional y democracia, Madrid: Centro de Estudios Constitucionales.

FIss, O. (1976). "Groups and the Equal Protection Clause," Philosophy and Public Affairs, 5 (2): $107-177$.

FISs, O. (1978). The Civil Rights Injunction, Bloomington: Indiana University Press.

Gardbaum, S. (2013). The New Commonwealth Model of Constitutionalism, Cambridge: Cambridge University Press. 
Gargarella, R. (1996). La justicia frente al gobierno, Barcelona: Ariel.

Gargarella, R. (2014). Por una justicia dialógica, Buenos Aires: Siglo XXI.

Gargarella, R. (2015). "We the People' Outside of the Constitution: The Dialogic Model of Constitutionalism and the System of Checks and Balances," Current Legal Problems (2014) 67(1): 1-47.

Gargarella, R. (2019). "Dialogic constitutionalism. A Critical and Comparative Approach”, manuscrito no publicado.

Gargarella, R. \& Niembro, R., (coords.) (2016). Constitucionalismo progresista. Un homenaje a Mark Tushnet México: UNAM.

Godoy, M. (2017). Devolver a Constituicao ao povo: critica a supremacia judicial e dialogos interinstitucionais. Belo Horizonte: Editora Forum.

González Bertomeu, J. (2011). "Against the Core of the Case: Structuring the Evaluation of Judicial Review” Legal Theory 17 (2):81-118.

Habermas, J. [1992] (1996), Between Facts and Norms, (Original Faktizität und Geltung), trad. W. Rehg, MIT Press, Cambridge, MA.

HogG, P. \& Busheld, A. (1997). "The Charter Dialogue Between Courts and Legislatures”, 35 Osgoode Hall L.J. 75.

Hogg, P.; Bushell, A. \& Wright, W. (2007). "Charter Dialogue Revisited, -Or much Ado About Metaphors”, 45 Osgoode Hall L.J. 1.

Hübner Mendes, C. (2011). "Neither Dialogue Nor Last Word: Deliberative Separation of Powers III", Legisprudence 5, 1.

Hübner Mendes, C. (2013). Constitutional Courts and Deliberative Democracy, Oxford: Oxford University Press.

Jaramillo, I. (2008). Mujeres, Cortes y Medios: La reforma judicial del aborto, Bogotá, Siglo del Hombre.

Kramer, L. (2004). "Popular Constitutionalism, Circa 2004, 92 California Le Review 959.

Kramer, L. (2005). The People Themselves. Popular Constitutionalism and Judicial Review, Oxford: Oxford U.P.

Linares, S. (2008). La (i)legitimidad democrática del control judicial de las leyes, Madrid: Marcial Pons.

Niembro, R. (2013). "Una mirada al constitucionalismo popular,” Isonomía, n. 38.

Nino, C. (1997). The Constitution of Deliberative Democracy, New Haven: Yale University Press.

Niembro, R. (2019). La justicia constitucional de la democracia deliberativa, Madrid: Marcial Pons.

Nino, C. (1992). Fundamentos de derecho constitucional, Buenos Aires: Astrea.

PArker, R. (1993). "Here, the People Rule, A Constitutional Populist Manifesto" Valparaiso University Law Review, vol. 27, n. 3, 531-84. 
Petter, A. (2003). "Twenty Years of Charter Justification: From Liberal Legalism to Dubious Dialogue” UNB Law Journal 52.

Post, R. \& Siegel, R. (2004). "Popular Constitutionalism, Departmentalism, and Judicial Supremacy”, Faculty Scholarship Series. Yale Law School,178.

Post, R. \& Siegel, R. (2007). "Roe Rage: Democratic Constitutionalism and Backlash,” Harvard Civil Rights-Civil Liberties Law Review, 42: 373.

Pou, F. (2011). "Justicia constitucional y protección de derechos en América Latina: el debate sobre la regionalización del activismo", en C. Rodríguez Garavito (coord.): El derecho en América Latina. Un mapa para el pensamiento jurídico del siglo XXI. Buenos Aires: Siglo XXI Editores, 231-250.

RoA RoA, J. (2019). Control de constitucionalidad deliberativo, Bogotá: Universidad Externado.

RoACH, K. (2001). "Constitutional and Common Law Dialogues Between the Supreme Court and Canadian Legislatures," 80 La Revue du Barreau Canadien 481.

RoACH, K. (2004). "Dialogic Judicial Review and its Critics," 23 Supreme Court Law Review, 49-104.

Rodríguez-Garavito, C. (2011). "Beyond the Courtroom: The Impact of Judicial Activism on Socioeconomic Rights in Latin America”, Texas Law Review, vol. 89, n. 7, 1669-1698.

Rosenberg, G. (1991). The Hollow Hope: Can Courts Bring About Social Change? Illinois: The University of Chicago Press.

SIEgEL, R. (1996). "The Rule of Love: Wife Beating as Prerogative and Privacy," Yale Law Journal 1018, 2117-2208

SIEgEL, R. (2004). "Equality Talk: Antisubordination and Anticlassification Values in Constitutional Struggles over Brown,” Harvard Law Review, 117: 1470.

Sunstein, C. (2001). "Social and Economic Rights? Lessons from South Africa," Chicago Unbound, University of Chicago Law School.

Thayer, J. (1893). "The Origin and Scope of the American Doctrine of Constitutional Law," Harvard Law Review. Vol. 7, No. 3 (Oct. 25), 129-156.

Tushnet, M. (1999). Taking the Constitution away from the Courts, Princeton: Princeton University Press.

Tushnet, M. (2008). Weak Courts, Strong Rights, Princeton: Princeton University Press.

Tushnet, M. (2009). 'Dialogic Judicial Review', 61 Ark. L. Rev. 205.

Tushnet, M. (2015). "New institutional mechanism for making Constitutional Law," Rochester, NY: Social Science Research Network, available at

http://papers.ssrn.com/sol3/papers.cfm?abstract_id=2589178

Unger, R. (1986). The Critical Legal Studies Movement, Harvard University Press.

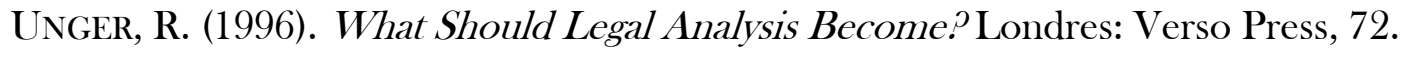

Waldron, J. (1993). “A Rights-Based Critique of Constitutional Rights,” Oxford Journal of Legal Studies, 13. 
Waldron, J. (1999). Law and Disagreement, Oxford: Oxford University Press.

Waldron, J. (1999b). The Dignity of Legislation, New York: Cambridge University Press.

Waldron, J. (2009). “The Core of the Case Against Judicial Review,” 115 Yale Law Journal 1348.

Young, K. (2012). Constituting Economic and Social Rights, Oxford: Oxford University Press. 